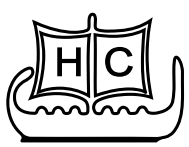

\title{
HISTORIA CARIBE
}

Índice Volumen XVI (2021)

Números 38 y $39^{1}$

Este índice comprende las dos últimas ediciones correspondientes al periodo 2021. Como puede darse cuenta el lector, por las diversas temáticas abordadas, esta publicación hace rato desbordó las fronteras locales y regionales alusivas al Caribe colombiano para transitar en el plano nacional e internacional.

El presente índice se encuentra organizado de la siguiente forma: primero se da cuenta del índice cronológico, el cual abarca el Volumen XVI integrado por los números 38 y 39, cuyos temas fueron para el caso del primero Dossier Universidades Populares y experiencias de extensión educativa en América Latina en la primera mitad del siglo $X X$ y para el segundo el Dossier Conflictividad y violencia política en América Latina (siglos $X X-X X I$ ). La segunda parte del índice se estructura por orden alfabético de autores.

\section{ÍNDICE CRONOLÓGICO}

\section{Artículos}

Vol. XVI No. 38 2021-1

Dossier: Universidades Populares y experiencias de extensión educativa en América Latina en la primera mitad del siglo $X X$

Yaverovski, Alejandro Martín. Tres Repúblicas Barriales y sus Universidades. Las Universidades Populares en la ciudad de Buenos Aires en el período de entreguerras: un esquema preliminar, 35-80.

1 Índice realizado por Eva Sandrin García Charris Magíster en Historia por la Universidad del Atlántico (Colombia). 
Scagliola, Gabriel. Las Universidades Populares en Uruguay (19301942), 81-106.

Cordoví Núñez, Yoel. La Universidad Popular José Martí en la órbita del pensamiento político de Julio Antonio Mella. Cuba, 1923-1927, 107-136.

González Sandoval, Leticia. Los estudiantes universitarios guatemaltecos y su proyección social: la Universidad Popular (1923-1932), 137-165.

Artieda, Teresa Laura. Historia de la Universidad Popular "Juan Ramón Lestani”' (Chaco, Argentina, circa 1929-1960), 167-208.

García Alonso, María. La extensión pedagógica en Iberoamérica como modelo de acción política: las misiones educativas laicas, 209-236.

\section{Tema Abierto}

Becerra Mora, José Camilo. Escritores Públicos y Prensa en la Nueva Granada, 1848-1853, 237-267.

Marín Ibarra, Mariana. Madres, pecadoras y obedientes: la formación religiosa de las poblanas en la primera mitad del siglo XIX mexicano, 269-298.

\section{RESEÑAS}

Teresa González Pérez (Coordinadora), La educación de las mujeres en Iberoamérica. Análisis histórico. Valencia: Tirant Humanidades, 2019.Vol. XVI No 38 Enero-Junio de 2021, 301-306. Juana María Rodríguez Gómez

Arno Burkholder, La red de los espejos. Una historia del diario Excélsior, 1916-1976. Ciudad de México: Fondo de Cultura Económica, 2016. Vol. XV No 38 Enero-Junio de 2021, 307-310. Katerinne Orquera Polanco 


\section{Artículos}

VoL. XVI N $392021-2$

Dossier: Conflictividad y violencia politica en América Latina (Siglos $X X-X X I)$

Henao Holguín, Diana. Empresarios agrícolas y campesinos colonos: colonización y conflicto agrario en la frontera Antioqueña (1926-1947), 23-58.

Goicovic Donoso, Igor. Inestabilidad, conflictividad y violencia política en chile, 1925-1941, 59-92.

Pozzi, Pablo Alejandro. "De frente, hacia las masas". El PRT-ERP y el trabajo de masas, 93-116.

Necoechea Gracia, Gerardo y Alicia De Los Ríos Merino. Violencia política y movilización popular: chihuahua (México), 1972, 117-151.

García Pérez, Patricio y García Sanhueza, Julián. Consideraciones acerca de los actores criminales de Colombia, como mutaciones del conflicto interno, desde la perspectiva económica y de la historia de las relaciones internacionales (2006-2018), 153-188.

\section{Tema Abierto}

De Marco, Celeste. ¿Qué es la niñez rural para la historia? Una revisión y una propuesta desde Argentina, 189-223.

Vargas Matías, Sergio A. Auge y ocaso de los protectores de la nación: el desmantelamiento del sistema fortificado de defensa de la provincia de Veracruz, México, 1822-1911, 225-262.

Manzano Iturra, Karen Isabel. La captura de la fragata María Isabel. El dilema de los barcos rusos y la independencia de Chile, 263-286. 
RESEÑAS

Luis Alarcón Meneses. Colombia: Historia, Educación y Política. Miradas Múltiples. Barranquilla: Sello Editorial Universidad del Atlántico, 2019. Vol. XVI N 39 Julio-Diciembre de 2021, 289-295. Jesús Ángel Castro Fontalvo

Juan Carlos Gaona Poveda. Disidencia religiosa y conflicto sociocultural. Tácticas y estrategias evangélicas de lucha por el modelamiento de la esfera pública en Colombia (1912-1957). Cali: Universidad del Valle, 2018. Vol. XVI No 39 Julio-Diciembre de 2021, 297-299. Osmir Ramírez Trillos

\section{ÍNDICE ALFABÉTICO DE AUTORES}

Artieda, Teresa Laura. No. 38, 167-208.

Becerra Mora, José Camilo. No. 38, 237-267.

Castro Fontalvo, Jesús Ángel. No. 39, 289-295 .

Cordoví Núñez, Yoel. No. 38, 107-136.

De Marco, Celeste. No. 39, 189-223.

De Los Ríos Merino, Alicia. No. 39, 117-151.

García Pérez, Patricio. No. 39, 153-188.

García Sanhueza, Julián. No. 39, 153-188

García Alonso, María. No. 38, 209-236.

González Sandoval, Leticia. No. 38, 137-165.

Goicovic Donoso, Igor. No. 39, 59-92.

Henao Holguín, Diana. No. 39, 23-58. 
Manzano Iturra, Karen Isabel. No. 39, 269-292.

Marín Ibarra, Mariana. No. 38, 269-298.

Necoechea Gracia, Gerardo. No. 39, 117-151.

Orquera Polanco, Katerinne. No. 38, 307-310

Pozzi, Pablo Alejandro. No. 39, 93-116.

Ramírez Trillos, Osmir. No. 39, 297-299.

Rodríguez Gómez, Juana María. No. 38, 301-306.

Scagliola, Gabriel. No. 38, 81-106.

Vargas Matías, Sergio A. No 39, 225-262.

Yaverovski, Alejandro Martín. No. 38, 35-80. 